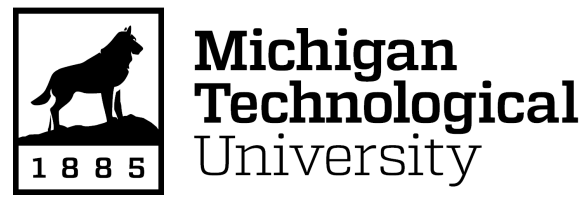

Michigan Technological University Digital Commons @ Michigan Tech

Global Conference of the Youth Environmental

Alliance in Higher Education

3rd YEAH Conference

Apr 21st, 1:15 PM - 1:24 PM

\title{
Session 2A Conservation and Preservation of the African Wild Donkey in Eritrea
}

Natalie McManus

Colorado State University

Carmen Bachofen

Colorado State University

Nick Godsey

Colorado State University

Miranda Rakes

Colorado State University

Follow this and additional works at: https://digitalcommons.mtu.edu/yeah-conference

\section{Recommended Citation}

McManus, Natalie; Bachofen, Carmen; Godsey, Nick; and Rakes, Miranda, "Session 2A Conservation and Preservation of the African Wild Donkey in Eritrea" (2021). Global Conference of the Youth Environmental Alliance in Higher Education. 35.

https://digitalcommons.mtu.edu/yeah-conference/april2021/all-events/35 


\section{Carmen Bachofen, Nick Godsey, Natalie McManus, Miranda Rakes}

\section{Background}

Eritrea is in the North Eastern part of Africa and relies heavily on aquatic and rain supported agricultural environments This makes Eritrea vulnerable to climate change because of droughts, land degradation, and deforestation.Native to Eritrea, The African Wild Ass (Equus africanus) is a wild member of the horse family and thought to be the earliest ancestor for the donkey. This species has been listed as critically endangered by the IUCN Red List and the population trend is decreasing. There is estimated to be 23-200 mature individuals. The African Wild Ass was chosen as an ecological indicator because it is heavily impacted by climate change and human impacts such as deforestation, desertification and urban sprawl. Humans are also impacted by climate change, deforestation, desertification and urban sprawl, so the population of Wild Ass would be a good indicator to how Eritrea is being impacted. Focusing on the Sustainable Development Goals (SDG), Sustainable Cities and Communities (11), Climate Action (13), and Life on Land (15), would be good goals for the conservation of the African Wild Ass.

Sustainable Development Goals

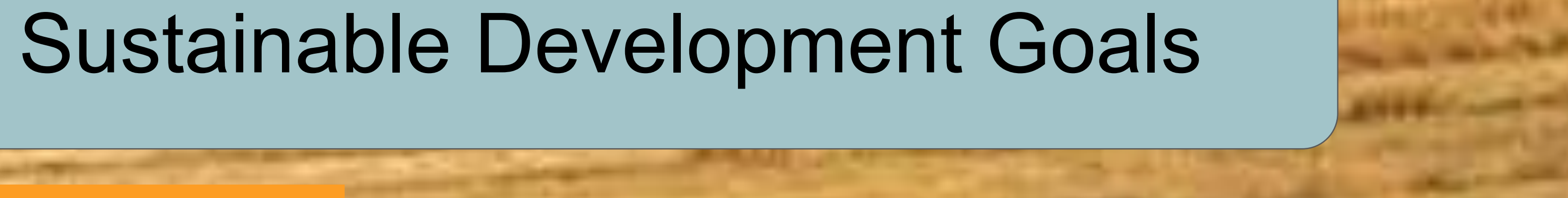

\section{Sustainable Cities \& Communities}

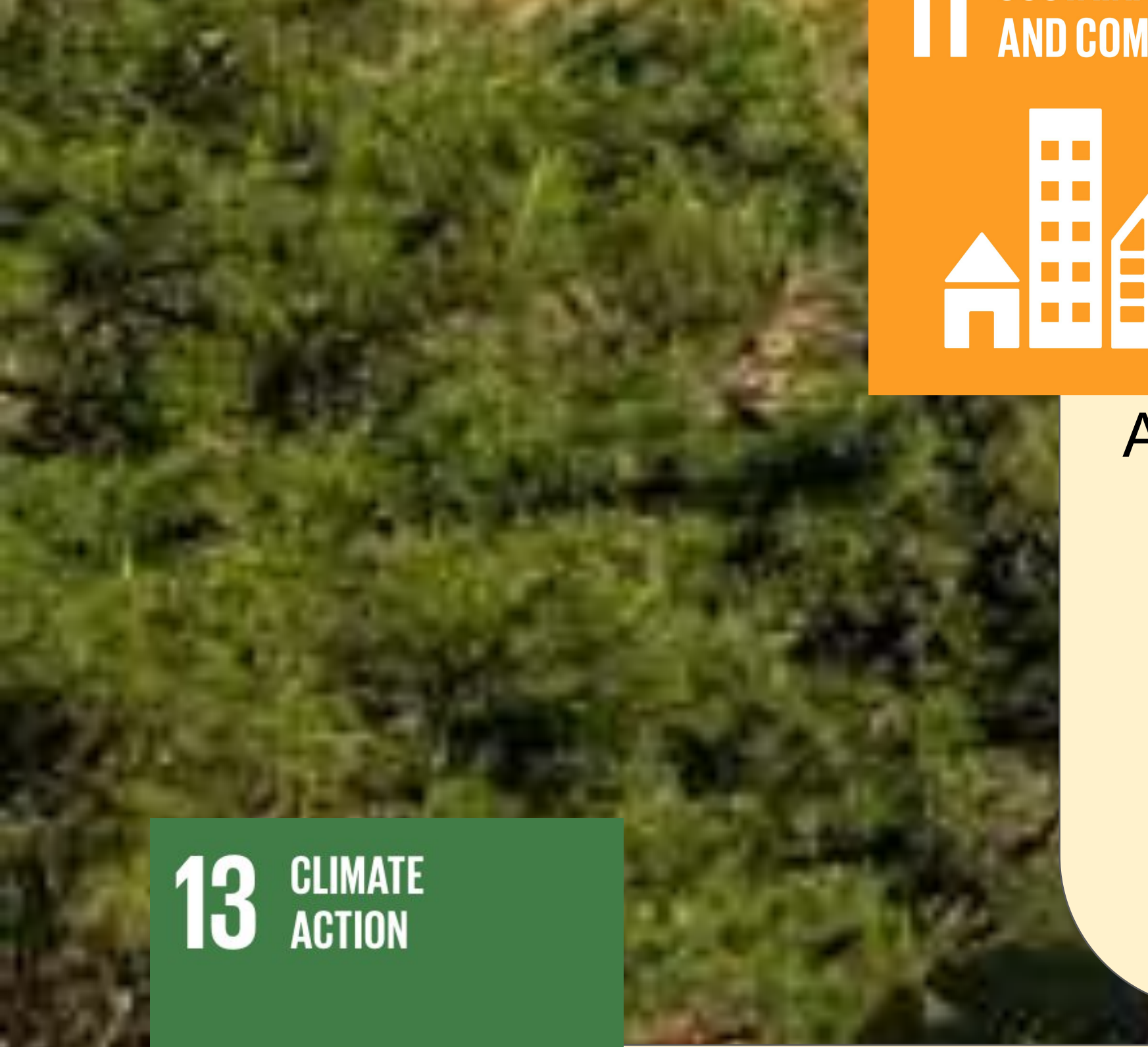
Unative ecosystems interact, it is communities to make them inclusive,
cortant to create sustainable cities and supportive, and safe for all species. As Eritrea is facing loss of habitat, desertification, and species decline, the increase in sustainable
cities will help protect land, its resources, and will help protect land, its resources, and
the species living on it.. Climate action is important to Eritrea as the mpact of climate change will heavily impact th more vulnerable. Working on SDG 13 will crisis. In Eritrea, this will promote and increase the ideas of protecting life on land and the creation of sustainable cities.

se
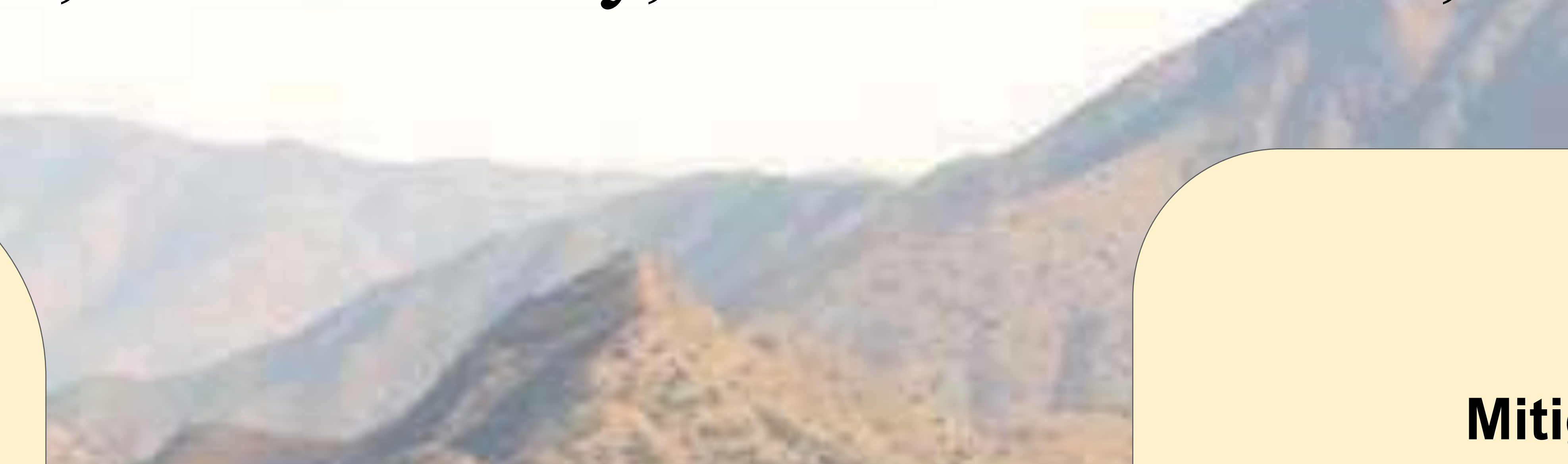

\section{Eritrea's INDC Goals}

\section{Mitigation, Adaptation, and Implementation}

Eritrea's INDC goals focus on the mitigation of greenhouses gases that are a large contributor to climate change. The country is also working to reduce its vulnerability to other climate change factors such as drought, desertification, and land degradation. There are plans in place for land rehabilitation as well as solar powered water systems, and more sustainable agriculture. Our indicator species, the African Wild Ass, would benefit from all of these goals as would the citizens of Eritrea. 